\title{
Interventions for the treatment of irritable bowel syndrome: a review of Cochrane systematic reviews
}

\author{
Ana Carolina Lemes SCACIOTA, Delcio MATOS, Manuelle Mastrorocco Brand ROSA, \\ Mileny Esbravatti Stephano COLOVATI, Elisa Fatima Benavent Caldas BELLOTTO and \\ Ana Luiza Cabrera MARTIMBIANCO
}

\begin{abstract}
Background - Irritable bowel syndrome (IBS) is a complex gastrointestinal disorder, whose understanding is relatively uncertain, and the treatment guidance decision still represents a challenge. Objective - To identify and critically appraise systematic reviews (SRs) published in the Cochrane Database of SRs (CDSR) on the effects of interventions (pharmacological and non-pharmacological) for the treatment of IBS. Methods - The search was conducted at the Cochrane Library in May 2020. The methodological quality of the SRs was evaluated by the AMSTAR-2 tool. Results - Eight SRs with moderate to high quality were included, which addressed the treatments: (a) pharmacological: volume agents, antispasmodics, antidepressants and tegaserod; and (b) non-pharmacological: homeopathy, acupuncture, phytotherapy, biofeedback, psychological interventions and hypnotherapy. The results were favorable to antispasmodic drugs and antidepressants regarding the improvement of clinical symptoms. There was no difference between volume agents or tegaserod when compared to placebo. Acupuncture and homeopathy showed a little improvement in symptoms compared to placebo, but the certainty of this evidence was considered low to very low. Psychological interventions seem to improve the overall assessment of the patient and relief symptoms such as abdominal pain. However, there was no long-term follow-up of these patients. The results of the other treatments were considered uncertain due to the high risk of bias. Conclusion - Considering the low quality of the studies included in the SRs, pharmacological treatment with antispasmodics and antidepressants seems to be beneficial for patients with IBS. Among non-pharmacological interventions, psychological interventions seem to be beneficial. However, further clinical trials are recommended with greater methodological rigor to prove these findings. HEADINGS - Irritable bowel syndrome. Systematic review. Evidence-based medicine.
\end{abstract}

\section{INTRODUCTION}

Irritable bowel syndrome (IBS) is a chronic functional gastrointestinal disorder, characterized by abdominal pain, swelling, constipation and changes in bowel habit. Symptoms vary among individuals and, for this reason, both diagnosis and treatment represent a challenge $\mathrm{e}^{(1-3)}$. Other common symptoms in patients with IBS include urinary frequency, chronic fatigue, sleep, and mood disorders, and may lead to the patient being mistakenly referred to other clinical specialties ${ }^{(4,5)}$.

It is estimated that the prevalence of IBS in the general population ranges from 1 to $45 \%$, depending on the country and its socioeconomic differences ${ }^{(6)}$. In Europe and North America, the prevalence of IBS was estimated between 10 and $15 \%$; in China 15.9\%. Data from South America are very scarce to reach a real conclusion, however, Uruguay had an overall prevalence of $10.9 \%$ and Venezuela $16.8 \%{ }^{(1)}$. The direct and indirect costs associated with IBS were estimated at more than one billion dollars a year in the United States ${ }^{(7)}$, and 6 to 8 billion euros per year in Europe ${ }^{(8)}$, which makes IBS a public health problem.

The physiological course of the disease is not yet fully known, since there is a wide variety of related mechanisms ${ }^{(1,2)}$. Psychological factors, changes in the connection of the central nervous system with the intestine, endocrine imbalance, visceral hypersensitivity, gastrointestinal infections and allergies and previous food intolerances are some of the criteria frequently analyzed. IBS occurs mainly between 15 and 65 years of age, and is more prevalent among women ${ }^{(3,4,6)}$.

Diagnosis is difficult, mainly because it is a syndrome with signs and symptoms common to various pathologies. Diagnostic criteria are based on Rome IV criteria, used for functional gastrointestinal disorders. According to these criteria, IBS is diagnosed based on recurrent abdominal pain related to defecation or associated with a change in the frequency or shape of feces ${ }^{(1,4,6)}$.

Currently, the treatment used for IBS varies according to clinical presentation, that is, there is no standard measure to be performed, both because of the difficulty in clarifying the etiopathogenesis and the heterogeneity of symptoms. However, the treatment covers non-pharmacological and pharmacological measures, including lifestyle changes, nutritional and behavioral guidelines, acupuncture, phytotherapy, possibly associated with medications such as antispasmodics, antidepressants, among others ${ }^{(5,6)}$. 
The importance of treatment for patients with IBS is due to the decrease in the impact on quality of life that symptoms can cause, impairing interpersonal and social relationships, productivity at work and routine activities. Therefore, the relevance of identifying and summarizing in a single document the studies of higher level of evidence on all possible therapeutic measures for the clinical recommendation in the treatment of IBS, contributing to the standardization of an adequate treatment with prognosis of improvement in the quality of life of these patients. Thus, the objective of this review was to identify and critically appraise the systematic reviews (SRs) published in the Cochrane Database of SRs (CDSR) on the effects of interventions (pharmacological and non-pharmacological) for the treatment of IBS.

\section{METHODS}

This review followed the recommendations of the Cochrane Handbook for Systematic Reviews of Interventions ${ }^{(9)}$ and PRISMA statement (Preferred Reporting Items for Systematic Reviews and Meta-Analyses) $)^{(10)}$.

\section{Criteria for inclusion of studies}

We included all systematic reviews (SRs) published by Cochrane on any pharmacological and non-pharmacological treatment for adult patients diagnosed with irritable bowel syndrome (IBS) were included. SRs that included mixed population, e.g. children and adults, or individuals with IBS and chronic constipation, were included only if the data were presented separately. All outcomes analyzed by the SRs were presented, including clinical and laboratory outcomes.

\section{Search strategy}

The search strategy was performed in the Cochrane Database of Systematic Reviews - CDSR (via Wiley) (on May 26, 2020) (FIGURE 1). There was no restriction on the date of publication. SRs in the protocol phase or marked as "withdrawn" from the Cochrane Library were not included.

\begin{tabular}{|c|c|}
\hline \multicolumn{2}{|c|}{ Search strategy } \\
\hline Cochrane Database of & MeSH descriptor: [Irritable Bowel \\
Systematic Reviews & Syndrome] explode all trees \\
(CDSR) (via Wiley) & [in Cochrane Reviews] \\
\hline
\end{tabular}

FIGURE 1. Search strategy.

\section{Selection of studies and data extraction}

The SRs identified in the search were selected by two independent reviewers (ACLS and MMBR), using the Rayyan online platform $^{(11)}$. The reviewers analyzed the titles and abstracts, and the SRs with eligibility potential were evaluated by reading the full text. In case of divergence, a third reviewer (ALCM or DM) decided to include or exclude the review. Two independent reviewers (EFBCB and MESC) extracted the data from the SRs using a previously prepared form containing information about the characteristics of the participants, interventions analyzed, comparison groups, outcomes, and results.

\section{Methodological quality assessment}

The methodological quality of the SRs was evaluated by two reviewers independently (ACLS and ALCM), using the AMSTAR-2 tool (Assessing the Methodological Quality of Systematic Reviews) ${ }^{(12)}$. This tool involves 16 items: (1) research question and inclusion criteria according to PICO (population, intervention, comparator and outcomes); (2) prior planning of the SR (protocol registration); (3) justification for the selection of the study design for inclusion; (4) comprehensive literature search strategy; (5) study selection in duplicate; (6) extraction of data in duplicate; (7) list of excluded studies; (8) details on the characteristics of the included studies; (9) methods used to assess the risk of bias in the included studies; (10) reporting of the funding sources of the included studies; (11) methods used to combine the results (meta-analysis); (12) assessment of the impact of the risk of bias in meta-analyses; (13) account for risk of bias in the interpretation and discussion of the results; (14) explanation of heterogeneity; (15) investigation of publication bias; and (16) report of conflict of interest for conducting the review. Each item is classified as: completely suitable ("yes"); partially adequate ("partially yes"), inadequate ("no") or not applicable. The domains 2, 4, 7, 9, 11, 13 and 15 were considered critical. The overall assessment of the quality of SRs takes into account the amount of critical flaws, and can be classified as critically low (More than one critical flaw), low (one critical flaw), moderate (more than one non-critical weakness) and high (one non-critical weakness). The evaluation was performed through the checklist available on the AMSTAR-2 website (http://amstar. ca/Amstar_Checklist.php).

\section{Summary of data}

The results of the included SRs were summarized narratively, considering the methodological quality evaluated by the AMSTAR 2 tool. Since each SRs included in this review evaluated a different intervention, there was no duplication of primary studies.

\section{RESULTS}

The search resulted in 19 systematic reviews (SRs), and 10 were excluded because they did not meet the inclusion criteria. Nine SRs were analyzed in full text and one was excluded for evaluating only individuals with constipation. Thus, eight $\mathrm{SRS}^{(13-20)}$ were included.

\section{Characteristics of systematic reviews included}

The eight SRs were published from 2007 to 2019, included only randomized clinical trials (RCTs) on pharmacological and non-pharmacological treatment for patients diagnosed with irritable bowel syndrome (IBS). Most RCTs presented an unclear risk of bias due to methodological limitations. The samples of the RCTs were predominantly of women, aged between 21 and 60 years and who had a minimum duration of symptoms between 3 and 6 months.

\section{Methodological quality of systematic reviews included}

Based on AMSTAR-2 tool assessment, most of the SRs were considered high quality ( $87.5 \%$ ), and only one was classified as moderate quality due to the absence of meta-analysis and investigation of publication bias. Three SRs $(37.5 \%)$ did not report the sources of funding for the included studies. The other items were presented appropriately. TABLE 1 showed the details of the evaluation. 
TABLE 1. Methodological quality assessment of the included systematic reviews with the AMSTAR-2 tool.

\begin{tabular}{|c|c|c|c|c|c|c|c|c|}
\hline \multirow[b]{2}{*}{ AMSTAR-2 } & \multicolumn{8}{|c|}{ Systematic reviews included } \\
\hline & $\begin{array}{l}\text { Ruepert } \\
2011^{(13)}\end{array}$ & $\begin{array}{c}\text { Evans } \\
2007^{(14)}\end{array}$ & $\begin{array}{l}\text { Manheimer } \\
2012^{(15)}\end{array}$ & $\begin{array}{c}\text { Peckham } \\
2019^{(16)}\end{array}$ & $\begin{array}{c}\text { Goldenberg } \\
2019^{(17)}\end{array}$ & $\underset{2006^{(18)}}{\text { Liu }}$ & $\begin{array}{c}\text { Zijdenbos } \\
2009^{(19)}\end{array}$ & $\begin{array}{l}\text { Webb } \\
2007^{(20)}\end{array}$ \\
\hline 1. Search question (PICO) & $\mathrm{Y}$ & $\mathrm{Y}$ & $\mathrm{Y}$ & $\mathrm{Y}$ & $\mathrm{Y}$ & $\mathrm{Y}$ & $\mathrm{Y}$ & $\mathrm{Y}$ \\
\hline 2. Study planning (protocol) & $\mathrm{Y}$ & Y & $\mathrm{Y}$ & $\mathrm{Y}$ & $\mathrm{Y}$ & $\mathrm{Y}$ & $\mathrm{Y}$ & $\mathrm{Y}$ \\
\hline 3. Justification for the selection of the study design & Y & Y & Y & $\mathrm{Y}$ & $\mathrm{Y}$ & Y & $\mathrm{Y}$ & Y \\
\hline 4. Search strategies & $\mathrm{Y}$ & Y & $\mathrm{Y}$ & $\mathrm{Y}$ & $\mathrm{Y}$ & Y & $\mathrm{Y}$ & Y \\
\hline 7. Report of excluded studies & $\mathrm{Y}$ & Y & $\mathrm{Y}$ & $\mathrm{Y}$ & Y & $\mathrm{Y}$ & $\mathrm{Y}$ & $\mathrm{Y}$ \\
\hline 8. Characteristics of the studies included & Y & Y & Y & $\mathrm{Y}$ & Y & Y & $\mathrm{Y}$ & Y \\
\hline 9. Risk of bias assessment & $\mathrm{Y}$ & Y & $\mathrm{Y}$ & Y & $\mathrm{Y}$ & $\mathrm{Y}$ & $\mathrm{Y}$ & $\mathrm{Y}$ \\
\hline $\begin{array}{l}\text { 10. Reporting of the sources of funding for the } \\
\text { studies }\end{array}$ & $\mathrm{N}$ & Y & $\mathrm{Y}$ & Y & $\mathrm{Y}$ & Y & $\mathrm{N}$ & $\mathrm{N}$ \\
\hline 13. Risk of bias in interpretation and results & Y & Y & Y & $\mathrm{Y}$ & $\mathrm{Y}$ & Y & Y & Y \\
\hline 14. Discussion and explanation of heterogeneity & Y & Y & Y & $\mathrm{Y}$ & $\mathrm{Y}$ & $\mathrm{Y}$ & $\mathrm{Y}$ & $\mathrm{Y}$ \\
\hline 15. Investigation of publication bias & $\mathrm{Y}$ & Y & $\mathrm{Y}$ & $\mathrm{Y}$ & $\mathrm{Y}$ & NA & $\mathrm{Y}$ & $\mathrm{Y}$ \\
\hline $\begin{array}{l}\text { 16. Report of conflict of interest of the authors of } \\
\text { the review }\end{array}$ & $\mathrm{Y}$ & Y & $\mathrm{Y}$ & $\mathrm{Y}$ & $\mathrm{Y}$ & $\mathrm{Y}$ & $\mathrm{Y}$ & $\mathrm{Y}$ \\
\hline Total (quality) & High & High & High & High & High & Moderate & High & High \\
\hline
\end{tabular}

PICO: population, intervention, comparator and outcomes; Y: yes; N: no; NA: not apply. Evaluated by the http://amstar.ca/Amstar_Checklist.php.

\section{Effects of interventions}

Pharmacological treatment

- Bulking agents, antispasmodics, antidepressants

One $\mathrm{SR}^{(13)}$ included 56 RCTs (3,725 patients), which evaluated the following drugs compared to placebo: bulking agents (12 RCTs), antispasmodics (29 RCTs) and antidepressants (15 $\mathrm{RCTs}$ ). The duration of the treatments ranged from 1 week to 6 months. In general, the risk of bias was classified between unclear and low. There were limitations mainly in the description of the methods used for randomization and allocation concealment (selection bias).

There was no beneficial effect of volume agents in relation to placebo for any of the outcomes analyzed, as well as between types of volume agents (soluble versus insoluble fibers). Overall, antispasmodics showed improvement in all outcomes. Data from individual studies showed statistically significant benefit for: cimetropium/dicyclomine, peppermint oil, pinaverium and trimebutin compared to placebo. As for antidepressants, there was also significant improvement in symptoms, especially for Selective serotonin reuptake inhibitor and tricyclic antidepressants.

\section{- Tegaserod}

One $\mathrm{SR}^{(14)}$ included $10 \mathrm{RCTs}$, with 8,598 patients diagnosed with predominant IBS-constipation. The overall risk of bias was unclear for most of the RCTs. Treatment with tegaserod (4 and $12 \mathrm{mg}$ ) was compared to placebo and lasted from 4 to 12 weeks.

Both tegaserod doses (4 and $12 \mathrm{mg}$ ) showed no difference compared to placebo for the improvement of abdominal pain. In the overall evaluation of the individual, tegaserod was higher than placebo after 4 weeks of treatment, with both doses. However, this improvement was not clinically significant. Regarding symptoms, the placebo group showed a significant reduction in diarrhea episodes compared to tegaserod. There was no difference between the groups for episodes of headache and nausea. The effects of tegaserod on gastrointestinal symptoms, such as swelling, stool consistency and exertion, were not consistent in the studies.

The estimates of the effect of meta-analyses for pharmacological treatments compared to placebo are detailed in TABLE 2.

\section{Non-pharmacological treatments \\ - Acupuncture}

This $\mathrm{SR}^{(15)}$ included a total of $17 \mathrm{RCTs}$, totaling 1806 participants, who compared acupuncture with placebo (sham), other active treatments or no treatment, in addition to acupuncture analysis as an adjunct to another treatment. In general, the risk of bias of the included RCTs was classified as low, except for five RCTs, which did not perform the randomization process adequately and the blinding of the participants and personnel. The certainty of the body of evidence, evaluated by the GRADE approach, was considered moderate due to the small sample size.

The results of the meta-analyses showed no benefits of acupuncture compared to placebo for both the improvement of symptom severity (standardized mean difference [SMD] -0.11, confidence interval [CI] 95\% -0.35 to 0.13 ; 4 RCTs; 281 patients), and for quality of life (SMD - $0.03 ; 95 \%$ CI -0.27 to $0.22 ; 3$ RCTs; 253 patients), after 3 to 10 weeks of treatment. There was improvement in symptoms in favor of acupuncture compared to pharmacological treatment (pinaverium bromide, sulfasalazine, trimebutine maleate), and no treatment (relative risk [RR] 2.11; 95\% CI 1.18 to $3.79 ; 2$ 
TABLE 2. Results of meta-analyses of pharmacological interventions compared to placebo for irritable bowel syndrome.

\begin{tabular}{|c|c|c|c|}
\hline \multirow{2}{*}{$\begin{array}{l}\text { Interventions } \\
\text { compared to placebo }\end{array}$} & \multicolumn{3}{|c|}{ Outcomes $[95 \% \mathrm{CI}]$} \\
\hline & Abdominal pain & Overall assessment & Symptom improvement \\
\hline Bulking agents & $\begin{array}{c}\text { There was no difference } \\
\text { SMD } 0.03[-0.34 \text { to } 0.40] \\
\text { 4 RCTs, } n=186\end{array}$ & $\begin{array}{l}\text { There was no difference } \\
\text { RR } 1.10[0.91 \text { to } 1.33] \\
11 \text { RCTs, } n=565\end{array}$ & $\begin{array}{c}\text { IBS score: there was no difference } \\
\text { SMD - } 0.00[-0.43 \text { to } 0.43] \\
3 \text { RCTs, } n=126\end{array}$ \\
\hline Antispasmodic & $\begin{array}{c}\text { Improvement in favor of intervention } \\
\text { RR } 1.32[1.12 \text { to } 1.55] \\
13 \text { RCTs, } n=1392\end{array}$ & $\begin{array}{c}\text { Improvement in favor of intervention } \\
\text { RR } 1.49\lfloor 1.25 \text { to } 1.77\} \\
22 \text { RCTs, } n=1983\end{array}$ & $\begin{array}{c}\text { IBS score: improvement in favor of } \\
\text { intervention } \\
\text { RR } 1.86[1.26 \text { to } 2.76] \\
4 \text { RCTs, } n=586\end{array}$ \\
\hline Antidepressants & $\begin{array}{c}\text { Improvement in favor of intervention } \\
\text { RR } 1.49[1.05 \text { to } 2.12] \\
\text { 8 RCTs, } \mathrm{n}=517\end{array}$ & $\begin{array}{c}\text { Improvement in favor of intervention } \\
\text { RR } 1.57[1.23 \text { to } 2.0] \\
11 \text { RCTs, } n=750\end{array}$ & $\begin{array}{c}\text { IBS score: improvement in favor of } \\
\text { intervention } \\
\text { RR } 1.99[1.32 \text { to } 2.99] \\
3 \text { RCTs, } \mathrm{n}=159\end{array}$ \\
\hline Tegaserode $4 \mathrm{mg}$ & $\begin{array}{c}\text { There was no difference } \\
\text { RR } 1.10[0.82 \text { to } 1.49] \\
3 \text { RCTs, } n=1675\end{array}$ & $\begin{array}{c}\text { Improvement in favor of intervention } \\
\text { RR } 1.15[1.02 \text { to } 1.31] \\
\text { 3 RCTs, } \mathrm{n}=1675\end{array}$ & $\begin{array}{c}\text { Bowel habits: improvement in favor } \\
\text { of intervention } \\
\text { RR } 1.21[1.02 \text { to } 1.43] \\
3 \text { RCTs, } \mathrm{n}=1675\end{array}$ \\
\hline Tegaserode $12 \mathrm{mg}$ & $\begin{array}{l}\text { There was no difference } \\
\text { RR } 1.16[0.89 \text { to } 1.51] \\
3 \text { RCTs, } n=1675\end{array}$ & $\begin{array}{c}\text { Improvement in favor of intervention } \\
\text { RR } 1.19[1.09 \text { to } 1.29] \\
\text { 4 RCTs, } n=3194\end{array}$ & $\begin{array}{c}\text { Bowel habits: there was no difference } \\
\text { RR } 1.10[0.93 \text { to } 1.31] \\
3 \text { RCTs, } n=1675\end{array}$ \\
\hline
\end{tabular}

RCTs: randomized clinical trials; n: number of participants; SMD: Standardized mean difference; RR: relative risk; 95\% CI: 95\% confidence interval; IBS score: Symptom score for Irritable Bowel Syndrome.

RCTs, 181 patients). However, the certainty of these evidence was considered low by the GRADE approach due to methodological limitations, small sample size and a wide confidence interval with imprecision of the results. There was no difference between acupuncture and probiotics, psychotherapy, as well as associated with other treatments of traditional Chinese medicine.

\section{- Homeopathy}

This $\mathrm{SR}^{(16)}$ included four RCTs (307 participants), two compared homeopathic treatment to placebo, and two to conventional treatment for patients with IBS-constipation. The risk of bias of RCTs was classified as unclear to low for most studies, and two did not blind the participants and personnel and had a high risk of bias for this domain. The certainty of the evidence was classified as very low by the GRADE approach due to methodological limitations, small sample size and the short follow-up period (2 weeks). Only one meta-analysis was conducted and showed very low quality evidence in favor of homeopathy compared to placebo for the overall improvement of IBS symptoms (RR 1.61; 95\%CI 1.18 to $2.18 ; 2$ RCTs, 129 participants). Individual data from the included RCTs showed no difference between homeopathy and conventional treatment. None of the studies reported abdominal pain, stool frequency, stool consistency or adverse events.

\section{- Biofeedback}

Biofeedback has been proposed as a therapy that can assist the individual in learning conscious control over sympathetic-vagal balance and symptom management. This $\mathrm{SR}^{(17)}$ included a total of eight RCTs, totaling 300 participants diagnosed with IBS. The risk of bias assessment varied between unclear and high.

Evidence of very low certainty has shown that the clinical benefits of biofeedback alone or associated with usual treatment, compared to the usual treatment alone or placebo are uncertain. A meta-analysis with data from three RCTs showed a benefit in favor of thermal biofeedback associated with cognitive behavioral therapy in the overall improvement of symptoms. However, the very low quality of evidence represents uncertainty about this result (mean difference [MD] 30.34; 95\%CI 8.47 to $52.21 ; 3$ RCTs, 101 participants). Only one RCT evaluated the quality of life of patients and reported no difference between treatment with biofeedback and cognitive behavioral therapy (RR $1.10 ; 95 \%$ CI 0.72 to 1.69 ; 2 RCTs, 80 participants). There were no reports of adverse events resulting from the intervention.

\section{- Phytotherapy}

This $\mathrm{SR}^{(18)}$ included $75 \mathrm{RCTs}$, involving 7,957 participants. Seventy-one different herbal medicines were tested in the included studies, and compared with: placebo, conventional pharmacological therapy or no treatment. The methodological quality of three double-blind, placebo-controlled studies was high, but the quality of the others was mostly low.

Since it was not possible to perform meta-analysis due to heterogeneity among the included RCTs, data from individual studies showed some benefit in reducing the symptoms of IBS reported by the patient in favor of herbal formulas (herbal compounds, standard Chinese formula, Tibetan formula Padma lax, ayurvedic preparation), compared to placebo. However, there was no difference between the groups in the improvement of abdominal pain and relief of constipation. Compared with conventional therapy, individual data from 65 RCTs testing 51 different herbal medicines showed little benefit in improving symptoms, but most studies showed no differences between groups. No adverse events related to herbal medicines have been reported.

Given the low methodological quality of the included studies, these results should be interpreted with caution and studies with greater rigor are necessary to support the findings of this SR.

\section{- Psychological interventions}

This $\mathrm{SR}^{(19)}$ included $25 \mathrm{RCTs}$, totaling 1,858 participants, comparing psychological interventions associated with conventional treatment or placebo, regarding symptom relief, improvement of abdominal pain and quality of life. The risk of bias was classified from unclear to high. The follow-up ranged from 2 to 3 months. Main findings: 
- Group psychological interventions versus conventional treatment or waiting list: significant improvement in favor of intervention in the overall assessment (RR 2.02; $95 \%$ CI 1.13 to $3.62 ; 2$ RCTs, 254 participants), in the symptom score (RR $0.62 ; 95 \%$ CI 0.45 to $0.79 ; 8$ RCTs, 593 participants) and in the relief of abdominal pain (SMD 0.26; 95\%CI 0.07 to $0.45 ; 10$ RCTs, 727 participants), after 3 months of treatment. There was no difference between the groups in improving quality of life, as well as in comparison with placebo.

- Cognitive behavioral therapy versus conventional treatment: significant improvement in favor of intervention in symptom improvement (MD 0.58; 95\% CI 0.36 to 0.79 ; 5 RCTs, 395 participants) after 3 months. There was no difference between the groups in abdominal pain and quality of life.

- Interpersonal psychotherapy and stress relaxation techniques were shown to be beneficial when compared to conventional treatment.

However, since the included studies did not evaluate the longterm results, there is no evidence that the effects of treatment will continue after the end of the treatments. The results of this SR should be analyzed with caution, as the clinically significant effect was not found for most outcomes. The studies showed substantial heterogeneity and small sample size.

\section{- Hypnotherapy}

This SR ${ }^{(20)}$ consisted of four RCTs including a total of 147 patients. Only one study compared hypnotherapy to an alternative therapy (psychotherapy and placebo pill), two studies compared hypnotherapy with waiting list control groups, and one study compared hypnotherapy to conventional medical treatment. The therapeutic effect of hypnosis was higher than that observed in the waiting list group, and when associated with conventional treatment, it was better than the conventional treatment alone. However, the data were not grouped in meta-analysis due to the heterogeneity among the included studies, which also have low methodological quality and small sample which led to high risk of bias. The quality of the studies was inadequate to allow any conclusion on the efficacy of hypnotherapy for IBS. Clinical trials with greater methodological rigor are still needed.

\section{DISCUSSION}

The present study mapped and summarized the evidence of Cochrane systematic reviews (SRs) on the different interventions for the treatment of irritable bowel syndrome (IBS) in adults. Cochrane's methodological rigor for the development and conduct of SRs is well established and recognized worldwide as the highest level of scientific evidence to support health decision-making. For this reason, we chose to include only SRs Cochrane, who, according to the AMSTAR-2 tool assessment, presented sufficient methodological quality to provide reliable information to the health professional and guide clinical practice.

The clinical variability of the characteristics and subtypes of IBS makes it difficult to decide on the best choices for the treatment of these patients. Of the eight SRs included, two analyzed the effects of pharmacological treatment for IBS. When comparing different classes of drugs with placebo, the results of meta-analyses showed significant improvement in symptoms and overall evaluation of patients with antispasmodics, antidepressants, and tegaserod. On the other hand, volume agents (soluble and insoluble fibers) showed no difference in any of the outcomes analyzed, and there was no improvement in abdominal pain and discomfort with the use of tegaserod.

Although both SRs were published more than 5 years without updating, a recent comprehensive review of literature ${ }^{(21)}$ on pharmacological treatments for IBS, published in 2020, showed similar results and corroborates these findings, that is, new studies were not sufficient to modify the results.

It is noteworthy that, among the SRs included on pharmacological treatment for IBS, only one evaluated safety through the rate of adverse events resulting from the intervention, and no difference was observed between tegaserod and placebo in episodes of nausea and headache.

Regarding non-pharmacological treatments, acupuncture has shown no benefit compared to placebo or other treatments such as probiotics, psychotherapy or other types of traditional Chinese medicine treatments. There was improvement in favor of acupuncture when compared to medications, but these results should be interpreted with caution because the certainty of the evidence was classified as low by the GRADE approach, due to methodological limitations in the studies analyzed. On the other hand, the evidence for homeopathy, despite showing some benefit in favor of the intervention, was classified as very low certainty, which represents in the GRADE approach an entire uncertainty in these findings. The same interpretation of the results should be considered for treatments with biofeedback, herbal medicines, and hypnosis. Finally, psychological interventions seem to be beneficial for patients with IBS, although the clinical significance of these results is debatable, as there was substantial heterogeneity between the studies, a fact that may compromise the external validity of the evidence.

Quality of life, despite being an important indicator of clinical improvement, was not evaluated by most of the primary studies included in the SR analyzed. Both quality of life and patient satisfaction are outcomes frequently reported by patients, and for this reason can be influenced by individual variables such as symptom severity, age, gender, socioeconomic status, among others. A systematic review published in 2020 showed that psychological interventions seem to improve the quality of life of patients with IBS. However, the authors reported the need to standardize the evaluation of this outcome in future studies ${ }^{(4)}$.

Most of the RCTs included in the SRs presented small sample size and methodological limitations related to randomization, blinding and lack in the description of losses during the study. These limitations can negatively influence the results and increase the risk of bias. The identification of the true effect of the interventions was also challenged by variations between the intervention and control groups, related to the different doses and treatment regimens, and especially the absence of long-term follow-up. Thus, most of the SRs included presented as implications for future research the conduction of further RCTs, strictly following the Consort statement ${ }^{(22)}$.

This review had as main limitation the restriction to the interventions analyzed by the Cochrane SRs, thus excluding some interventions that were not studied in these SRs, for example, nutritional diets, exercises, probiotics, some classes of medications, as well as other alternative therapies. It is important to highlight that, given the low certainty of evidence, therapeutic choice should be based on an effective doctor-patient relationship, and the combination of pharmacological and non-pharmacological interventions seems to be an alternative to be considered individually. 


\section{CONCLUSION}

Considering the low quality of primary studies analyzed in the included SRs, pharmacological treatment with antispasmodics and antidepressants seems to be beneficial for patients with IBS in relation to the improvement of clinical symptoms. Among nonpharmacological interventions, psychological interventions seem to be beneficial. The results of the other treatments were considered uncertain due to the high risk of bias. All the included SRs recommended as implications for research new clinical trials with greater methodological rigor to prove these findings. Adverse events and quality of life are fundamental outcomes and need to be evaluated in future studies, as well as the clinical effects of long-term interventions.

\section{Authors' contribution}

Scaciota ACL: conceptualization, resources, data collection, writing-original draft. Matos D: conceptualization, methodology, writing-review and editing. Rosa MMB: resources, data collection, writing-original draft. Colovati MES: conceptualization, methodology, writing-review and editing. Bellotto EFBC: data collection, formal analysis; writing-review and editing. Martimbianco ALC: conceptualization, methodology, data collection, project administration, writing-review and editing.

\section{Orcid}

Ana Carolina Lemes Scaciota: 0000-0001-8722-8582.

Délcio Matos: 0000-0003-0117-8786.

Manuelle Mastrorocco Brand Rosa: 0000-0001-8651-9257.

Mileny Esbravatti Stephano Colovati: 0000-0001-9531-6144.

Elisa Fatima Benavent Caldas Bellotto: 0000-0001-5335-1291.

Ana Luiza Cabrera Martimbianco: 0000-0002-4361-4526.

Scaciota ACL, Matos D, Rosa MMB, Colovati MES, Bellotto EFBC, Martimbianco ALC. Intervenções para o tratamento da síndrome do intestino irritável: revisão de revisões sistemáticas Cochrane. Arq Gastroenterol. 2021;58(1):120-6.

RESUMO - Contexto - A síndrome do intestino irritável (SII) é um distúrbio gastrointestinal complexo, cujo entendimento é relativamente incerto e a decisão de orientação do tratamento ainda representa um desafio. Objetivo - Identificar e avaliar criticamente as revisões sistemáticas (RSs) publicadas na base de dados de RSs Cochrane (CDSR) sobre os efeitos das intervenções (farmacológicas e não farmacológicas) para o tratamento da SII. Métodos - A busca foi realizada na Biblioteca Cochrane em maio de 2020. A qualidade metodológica das RSs foi avaliada pela ferramenta AMSTAR-2. Resultados - Foram incluídas oito RSs com qualidade moderada a alta, as quais abordaram os tratamentos: (a) farmacológico - agentes de volume, antiespasmódicos, antidepressivos e o tegaserod; e (b) não farmacológico - homeopatia, acupuntura, fitoterapia, biofeedback, intervenções psicológicas e hipnoterapia. Os resultados foram favoráveis aos medicamentos antiespasmódicos e antidepressivos em relação à melhora dos sintomas clínicos. Não houve diferença entre os agentes de volume ou tegaserod quando comparados ao placebo. Acupuntura e homeopatia apresentaram pequena melhora dos sintomas em comparação ao placebo, porém a qualidade da evidência foi considerada baixa a muito baixa. As intervenções psicológicas parecem melhorar a avaliação global do paciente e alívio de sintomas como dor abdominal. Contudo, não houve acompanhamento desses pacientes a longo prazo. Os resultados dos demais tratamentos foram considerados incertos devido ao alto risco de viés. Conclusão - Considerando a baixa qualidade dos estudos incluídos nas RSs, o tratamento farmacológico com antiespasmódicos e antidepressivos parece ser benéfico para os pacientes com SII. Entre os não-farmacológicos, as intervenções psicológicas parecem obter benefícios. Entretanto, novos ensaios clínicos são recomendados com maior rigor metodológico para comprovar estes achados.

DESCRITORES - Síndrome do intestino irritável. Revisão sistemática. Medicina baseada em evidências.

\section{REFERENCES}

1. World Gastroenterology Organisation Global Guidelines. Irritable Bowel Syndrome: a Global Perspective. September 2015. [Internet]. [Accessed 2019 August 08]. Available from: https://www.worldgastroenterology.org/UserFiles/ file/guidelines/irritable-bowel-syndrome-english-2015.pdf

2. Ooi AL, Correa D, Pak SC. Probiotics, Prebiotics, and Low FODMAP Diet for Irritable Bowel Syndrome - What Is the Current Evidence? Complement Ther Med. 2019;43:73-80

3. Ford AC, Lacy BE, Talley NJ. Irritable Bowel Syndrome. N Engl J Med. 2017;376:2566-78.

4. Cassar GE, Youssef GJ, Knowles S, Moulding R, Austin DW. Health-Related Quality of Life in Irritable Bowel Syndrome: A Systematic Review and Meta-analysis. Gastroenterol Nurs. 2020;43:E102-E22.

5. Ribeiro LM, Alves NG, Silva-Fonseca VA, Nemer ASA. Influence of individual response to stress and psychiatric comorbidity in irritable bowel syndrome. Rev Psiq Clín. 2011;38:77-83.

6. Lovell RM, Ford AC. Global prevalence of and risk factors for irritable bowel syndrome: a meta-analysis. Clin Gastroenterol Hepatol. 2012;10:712-21

7. Everhart JE, Ruhl CE. Burden of digestive diseases in the United States part I: overall and upper gastrointestinal diseases. Gastroenterology. 2009;136:376-86.

8. Flacco ME, Manzoli L, De Giorgio R, Gasbarrini A, Cicchetti A, Bravi F, et al Costs of irritable bowel syndrome in European countries with universal healthcare coverage: a meta-analysis. Eur Rev Med Pharmacol Sci. 2019;23:2986-3000.
9. Higgins JPT, Thomas J, Chandler J, Cumpston M, Li T, Page MJ, Welch VA (editors). Cochrane Handbook for Systematic Reviews of Interventions version 6.0 (updated July 2019). Cochrane, 2019.

10. Moher D, Liberati A, Tetzlaff J, Altman DG, Group P. Preferred reporting items for systematic reviews and meta-analyses: the PRISMA statement. PLoS med. Public Library of Science; 2009;6(7):e1000097.

11. Mourad Ouzzani, Hossam Hammady, Zbys Fedorowicz, and Ahmed Elmagarmid. Rayyan — a web and mobile app for systematic reviews. Systematic Reviews. 2016;5:210.

12. Shea BJ, Reeves BC, Wells G, Thuku M, Hamel C, Moran J, et al. AMSTAR 2: a critical appraisal tool for systematic reviews that include randomised or non-randomised studies of healthcare interventions, or both. BMJ. 2017;358:j4008.

13. Ruepert L, Quartero AO, de Wit NJ, van der Heijden GJ, Rubin G, Muris JWM. Bulking agents, antispasmodics and antidepressants for the treatment of irritable bowel syndrome. Cochrane Database of Systematic Reviews 2011, Issue 8. Art. No.: CD003460.

14. Evans BW, Clark WK, Moore DJ, Whorwell PJ. Tegaserod for the treatment of irritable bowel syndrome and chronic constipation. Cochrane Database of Systematic Reviews 2007, Issue 4. Art. No.: CD003960.

15. Manheimer E, Cheng K, Wieland LS, Min LS, Shen X, Berman BM, Lao L. Acupuncture for treatment of irritable bowel syndrome. Cochrane Database of Systematic Reviews 2012, Issue 5. Art. No.: CD005111. 
16. Peckham EJ, Cooper K, Roberts ER, Agrawal A, Brabyn S, Tew G. Homeopathy for treatment of irritable bowel syndrome. Cochrane Database of Systematic Reviews 2019, Issue 9. Art. No.: CD009710.

17. Goldenberg JZ, Brignall M, Hamilton M, Beardsley J, Batson RD, Hawrelak J, Lichtenstein B, Johnston BC. Biofeedback for treatment of irritable bowel syndrome. Cochrane Database of Systematic Reviews 2019, Issue 11. Art. No.: CD012530.

18. Liu JP, Yang M, Liu Y, Wei ML, Grimsgaard S. Herbal medicines for treatment of irritable bowel syndrome. Cochrane Database of Systematic Reviews 2006, Issue 1. Art. No.: CD004116.

19. Zijdenbos IL, de Wit NJ, van der Heijden GJ, Rubin G, Quartero AO. Psychological treatments for the management of irritable bowel syndrome. Cochrane Database of Systematic Reviews 2009, Issue 1. Art. No.: CD006442.
20. Webb AN, Kukuruzovic R, Catto-Smith AG, Sawyer SM. Hypnotherapy for treatment of irritable bowel syndrome. Cochrane Database of Systematic Reviews 2007, Issue 4. Art. No.: CD005110.

21. Chen M, Tang T-C, Qin D, Yue L, Zheng H. Pharmacologic treatments for irritable bowel syndrome: an umbrella systematic review. J Gastrointestin Liver Dis. 2020;29:199-209.

22. Schulz KF, Altman DG, Moher D, for the CONSORT Group. CONSORT 2010 Statement: updated guidelines for reporting parallel group randomised trials. J Clin Epidemiol. 2010;63:834-40. 